\title{
Role of the GRO Family of Chemokines in Monocyte Adhesion to MM-LDL-Stimulated Endothelium
}

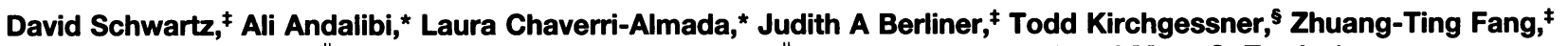 \\ Patricia Tekamp-Olson," Aldons J. Lusis, ${ }^{*}$ Carol Gallegos," Alan M. Fogelman," and Mary C. Territo* \\ Departments of ${ }^{*}$ Medicine and ${ }^{\ddagger}$ Pathology, Center for the Health Sciences, University of California at Los Angeles, Los Angeles, \\ California 90024; Bristol-Myers Squibb, ${ }^{8}$ Department of Metabolic Diseases, Princeton, New Jersey 08543; and $"$ Chiron Corporation, \\ Emeryville, California 94608
}

\begin{abstract}
We have previously shown that treatment of endothelial cells with minimally modified LDL (MM-LDL) induces the binding of monocytes to unknown endothelial receptor molecules. We now report that a member of the GRO family of chemokines plays a role in MM-LDL-induced monocyte binding. A cDNA library made from rabbit aortic endothelial cells (RAEC) treated with MM-LDL was expression screened for molecules inducing binding of a human monocyte cell line (THP-1). A cDNA was isolated with $75 \%$ homology to GRO. GRO mRNA levels were significantly elevated after exposure of RAEC or human aortic endothelial cells (HAEC) to MM-LDL. HAEC treated with MM-LDL displayed an increase in a surface-associated protein that bound to antibody against GRO despite low levels of GRO in the medium. Antibody to GRO significantly inhibited the binding of monocytes to MM-LDL-treated RAEC and HAEC. The increase in GRO expression and monocyte binding were reduced by incubating MM-LDL-treated endothelial cells with heparin (in a method that releases heparan sulfate bound molecules from the cell surface). These results suggest that GRO related chemokines are bound to the surface of MM-LDL-treated endothelial cells and may contribute to the monocyte adhesion induced by MM-LDL. (J. Clin. Invest. 1994. 94:1968-1973.) Key words: GRO • monocytes - endothelium • adhesion factors • chemokines
\end{abstract}

\section{Introduction}

Considerable evidence has linked oxidative modification of low density lipoproteins (LDL) with early fatty streak formation (see reference 1 for review). Recent studies in our laboratory

Address correspondence to Dr. Mary Territo, UCLA School of Medicine, CHS 42-121, Los Angeles, CA 90024. 1994.

Received for publication 3 March 1994 and in revised form 29 May

1. Abbreviations used in this paper: cNPP; paranitrophenylphosphate; ECGS, endothelial cell growth substance; ELAM, endothelial leukocyte adhesion molecule; $\alpha \mathrm{FGF}$, alpha fibroblast growth factor; HAEC, human aorta endothelial cells; HSPG, heparan sulfate proteoglycan, ICAM, intracellular adhesion molecule; MCP-1, monocyte chemotactic protein 1; M-CSF, macrophage colony-stimulating factor; MIP, macrophage inflammatory protein; MM-LDL, minimally modified LDL; RAEC, rabbit aortic endothelial cell; VCAM, vascular cell adhesion molecule.

J. Clin. Invest.

(c) The American Society for Clinical Investigation, Inc. 0021-9738/94/11/1968/06 \$2.00

Volume 94, November 1994, 1968-1973 have focused on the atherogenic properties of LDL which is mildly oxidized, minimally modified LDL (MM-LDL) ${ }^{1}$. These studies have demonstrated that MM-LDL induces the binding of monocytes to the endothelium $(1,2)$, and stimulates the production of monocyte colony stimulating factor (M-CSF) and monocyte chemotactic protein-1 (MCP-1) by endothelial cells (3-5). The identity of the binding molecules induced by MMLDL is not known, but these molecules have been shown to be distinct from vascular cell adhesion molecule (VCAM-1), E Selectin/endothelial leukocyte adhesion molecule (ELAM-1), intracellular adhesion molecule (ICAM-1), and MCP-1 (6). Because interactions between circulating leukocytes and the vascular wall are believed to play a crucial role in regulating early atherogenesis, we have undertaken studies to identify these molecules.

In an attempt to define the molecules responsible for the MM-LDL-induced monocyte adhesion, we utilized an expression cloning system with a cDNA library prepared from rabbit aortic endothelial cells which had been stimulated with MMLDL. As will be detailed below, screening of this library with a COS-7 cell-monocyte adhesion assay resulted in the isolation of a cDNA clone with striking homology to the human GRO proteins and to murine KC. Subsequently, it was shown that MM-LDL induces the production of $\mathrm{KC}$ in mouse $\mathrm{L}$ cells (7).

The GRO proteins are members of the chemokine superfamily, a family of small, heparin-binding cytokines related to human platelet factor 4 and expressed as primary response gene products (for review, see reference 8). Several members of this family, including the human GRO molecules GRO $\alpha$, GRO $\beta$, GRO $\gamma$, and the murine molecules $\mathrm{KC}$ and macrophage inflammatory protein-2 (MIP-2) show high sequence homology and cross-hybridization in Southern and Northern blotting (911). These peptides have all been implicated in inflammatory signaling and growth modulation. They are produced by, and act upon, multiple cell types. Enhanced GRO protein expression has been previously demonstrated in cytokine and LPS-stimulated human umbilical vein endothelial cells and monocytes (911). After being initially characterized as an autocrine growth factor secreted by a human melanoma cell line (12), GRO proteins were subsequently shown to be chemotactic for neutrophils (13-15) and to induce a respiratory burst in monocytes (16). This study examines the ability of MM-LDL to increase the expression of GRO in endothelial cells and examines a possible role of this chemokine family in monocyte-endothelial cell adhesion.

\section{Methods}

Cells. Rabbit aortic endothelial cells (RAEC) at passage $<18$ and human aortic endothelial cells (HAEC) at passages 5-12 were cultured as described previously $(2,4)$. For these studies, human monocytes were isolated by a modification of the Recalde method (17). Cells from the 
human monocytic cell line THP-1 were obtained from American Type Culture Collection (ATCC No. TIB 202) (Rockville, MD).

Chemokines and antibodies. Two antibodies were employed for cell surface ELISA assays: $(a)$ a rabbit polyclonal antibody raised against human GRO $\beta$ and $\gamma$ which also recognizes GRO $\alpha$ (Chiron Corp., Emeryville, CA), and (b) a monoclonal antibody raised against GRO $\alpha$ that reacts with GRO $\beta$ and $\gamma$ on formalin-fixed cells (a gift from Dr. Ann Richmond, Vanderbilt University). For assays of GRO levels in medium, a monoclonal antibody to GRO (2E3, Chiron Corp.) was used. These antibodies did not react with MCP-1 using dot blot assay. Monoclonal antibody 2E3 and polyclonal GRO antiserum were not crossreactive with IL-8 in a capture ELISA. For ELISA assays of MCP-1 in media and on the cell surface, a polyclonal antibody raised to baboon MCP-1 was used (antibody obtained from Dr. A. J. Valente, University of Texas, San Antonio). By dot blot assay, this antibody did not react with GRO peptides.

Preparation of $M M-L D L$. MM-LDL was prepared from human native LDL by a modification of the method of Sparrow et al. (18) involving treatment of LDL with soybean lipoxygenase and phospholipase $A_{2}$ (19).

Northern blot analysis. RNA was prepared from whole cells and 10 $\mu \mathrm{g}$ run in each lane. For studies on RAEC, RNA was probed on Northern blots (20) using the linearized cDNA from the GRO-related clone that was isolated from the MM-LDL-stimulated RAEC library (Fig. 1). For studies on HAEC, RNA was probed on Northern blots using a full length cDNA probe made to human GRO $\beta$ that also reacted with GRO $\alpha$ and GRO $\gamma$ mRNA (Chiron Corp.).

Expression screening of the $C D N A$ library from $M M-L D L$ treated cells. An expression library was constructed using Poly A+ RNA from RAEC treated for $4 \mathrm{~h}$ with MM-LDL. cDNA was synthesized by the method of Guebler and Hoffman (21) and DNA $>1 \mathrm{~kb}$ was ligated into the expression vector PCDM8 using a BSTX-1 adaptor; this plasmid was used to transform Escherichia coli. The resultant library contained $5 \times 10^{6}$ recombinants with an average insert size of $1.5 \mathrm{~kb}$. The library was transfected into Cos-7 cells and screened for the binding of THP1 cells (a monocytic line) as described previously $(22,23)$. Cells binding six or more THP-1 cells were picked under an inverted microscope; Hirt supernatants were prepared from them and the plasmid DNA electroporated into $E$. coli. This process was repeated and cDNA was isolated from the resulting 530 bacterial colonies, transfected into COS cells, and screened for THP-1 binding.

Measurement of surface-associated GRO protein and MCP-1. HAEC were grown to confluence in 96-well plates (Costar Corp., Cambridge, MA) in medium 199 with 5\% FCS, ECGS, and heparin at $37^{\circ} \mathrm{C}$. Fresh media 199 containing 10\% FCS was added to the cells before overnight incubation. The following morning, the medium was changed to media 199 with $10 \%$ FCS containing $125 \mu \mathrm{g} / \mathrm{ml} \mathrm{MM-LDL} \mathrm{(test}$ wells), $1 \mathrm{ng} / \mathrm{ml}$ LPS (positive control), or no additive (negative control). After $4 \mathrm{~h}$ of incubation, one of three procedures were followed: $(a)$ cells were directly incubated with a 1:10,000 dilution of polyclonal antibody to GRO; $(b)$ cells were fixed for 30 min with cold $4 \%$ formaldehyde, rinsed, and incubated with a 1:20 or 1:30 dilution of GRO monoclonal antibody; (c) Cells were incubated directly with a 1:1000 dilution of antibody to MCP-1. The primary antibodies were removed, the cells rinsed and incubated with the secondary antibody complexed to alkaline phosphatase. The alkaline phosphatase was detected with $1 \mathrm{mg} / \mathrm{ml}$ paranitrophenylphosphate (pNPP) in $10 \%$ diethanolamine, $0.1 \%$ levamisole. Plates were left overnight at room temperature and read the next day at $405 \mathrm{~nm}$ using an automated microplate reader (Molecular Devices Corp., Sunnyvale, CA). This fixation procedure did not allow antibody staining of Factor VIII antigen (a cytoplasmic molecule) unless the cells were initially permeabilized with methanol, indicating that this ELISA protocol detected only surface-associated proteins.

Assays of GRO and MCP-1 in the medium. Secreted GRO was assayed by ELISA as follows. The capture antibody was a 1:100 dilution of purified IgG from ascites of a murine monoclonal antibody (2E3), raised against recombinant human GRO $\beta$. Samples, suitably diluted, were incubated for $2 \mathrm{~h}$ at $37^{\circ} \mathrm{C}$, washed, and incubated for $1 \mathrm{~h}$ at $37^{\circ} \mathrm{C}$ with rabbit anti-GRO $(\beta / \gamma)$ polyclonal antisera at a 1:200 dilution.
Signal was detected following incubation for $1 \mathrm{~h}$ at $37^{\circ} \mathrm{C}$ with goat anti-rabbit IgG and then reacted with nitrophenyl phosphate. After reaction termination, plates were read on a Molecular Devices plate reader at $492 \mathrm{nM}$. The sensitivity of this ELISA is $\sim 0.3 \mathrm{ng} / \mathrm{ml}$ for GRO $\beta$ and is two to four times greater for Gro $\beta$ compared with GRO $\alpha$ or GRO $\gamma$ when tested against purified recombinant proteins. MCP1 was assayed by previously described methods $(24,25)$.

Leukocyte-endothelial binding assay. RAEC and HAEC were grown in 48-well tissue culture plates in DME containing $10 \%$ calf serum (for RAEC) or medium 199 containing 10\% FCS (for HAEC), with or without $125 \mu \mathrm{g} / \mathrm{ml} \mathrm{MM-LDL}$ or $1 \mathrm{ng} / \mathrm{ml}$ LPS, and incubated for $4 \mathrm{~h}$ at $37^{\circ} \mathrm{C}$. All wells were rinsed with warm media 199 containing serum just before the addition of leukocytes. Leukocytes $\left(10^{5}\right)$ were added to each well for $10 \mathrm{~min}$ at $37^{\circ} \mathrm{C}$. Unbound cells were rinsed off and the wells were fixed with $2 \%$ glutaraldehyde in PBS. The number of attached leukocytes in four low-powered microscopic fields was counted for each of three wells for each treatment.

To study the effect of antibodies directed against human GRO proteins, the endothelial cells were exposed to $125 \mu \mathrm{g} / \mathrm{ml} \mathrm{MM-LDL,} 1 \mathrm{ng} /$ $\mathrm{ml}$ LPS, or no additive for $4 \mathrm{~h}$. The monolayers were washed with medium 199 containing $10 \% \mathrm{FCS}$, and the antibodies at $1: 100$ or $1: 1000$ dilutions were added to appropriate wells for an additional $15 \mathrm{~min}$ at $37^{\circ} \mathrm{C}$. The wells were washed and then leukocytes $\left(10^{5}\right)$ were added to each well and incubated for $10 \mathrm{~min}$ at $37^{\circ} \mathrm{C}$. Preimmune rabbit serum was used as a control in appropriate wells. The plates were subsequently washed, fixed, and counted as described above.

Heparin treatment of endothelial cell monolayers. We attempted to displace GRO from the endothelial surface using conditions similar to those shown to displace lipoprotein lipase (a heparin sulfate bound protein) from the endothelial surface (26). MM-LDL treated HAEC were exposed to heparin (Sigma H3125; Sigma Chemical Co., St. Louis, MO) at $100 \mu \mathrm{g} / \mathrm{ml}$ for $8 \mathrm{~min}$ before the addition of monocytes to assess monocyte adhesion as described above, or before determination of the surface expression of GRO by ELISA assay using GRO polyclonal antibody as described above.

\section{Results}

In order to clone the molecules that might mediate the monocyte binding induced by MM-LDL, a cDNA library was constructed from MM-LDL-treated RAEC. This library was screened in a COS cell expression system for the ability of CDNA to induce the binding of THP- 1 cells (a monocytic cell line), but not HL60 cells (a human neutrophil cell line). One clone was selected from this screening and sequenced. The nucleotide sequence is available in Genbank (Accession No. RABGRO U12310). The resultant protein sequence was found to be almost $75 \%$ homologous to the human GRO proteins (GRO $\alpha$, GRO $\beta$, and GRO $\gamma$ ), and also to a partial sequence of a previously reported rabbit cytokine RPF2-49-50 (27) (Fig. 1).

mRNA for a GRO homologue is increased in aortic endothelial cells by minimally-modified $L D L$. Using Northern blot analysis, expression of mRNA for the GRO homologue was determined in RAEC treated for 1-24 h with $125 \mu \mathrm{g} / \mathrm{ml}$ of $\mathrm{MM}$ LDL. Only one band was observed for the mRNA of this rabbit GRO homologue which was about $1 \mathrm{~kb}$ in size. Induction of expression was first evident at $2 \mathrm{~h}$, became maximal at $4 \mathrm{~h}$ ( $\sim 25 \times$ control), and was substantially decreased by $6 \mathrm{~h}$ (Fig. $2 A$ ). By hybridization with a probe made to human Gro $\beta$, HAEC showed a maximal induction of mRNA by $1 \mathrm{~h}(\approx 6$ $\times$ control) and levels remained elevated for $24 \mathrm{~h}$ (Fig. $2 \mathrm{~B}$ ).

$M M-L D L$ induces the surface expression of a GRO homologue but not MCP-1 on human aortic endothelial cells. In order to detect and quantify the induction of surface-associated proteins, HAEC monolayers were stimulated with MM-LDL or LPS and subjected to ELISA assay using polyclonal antibody 


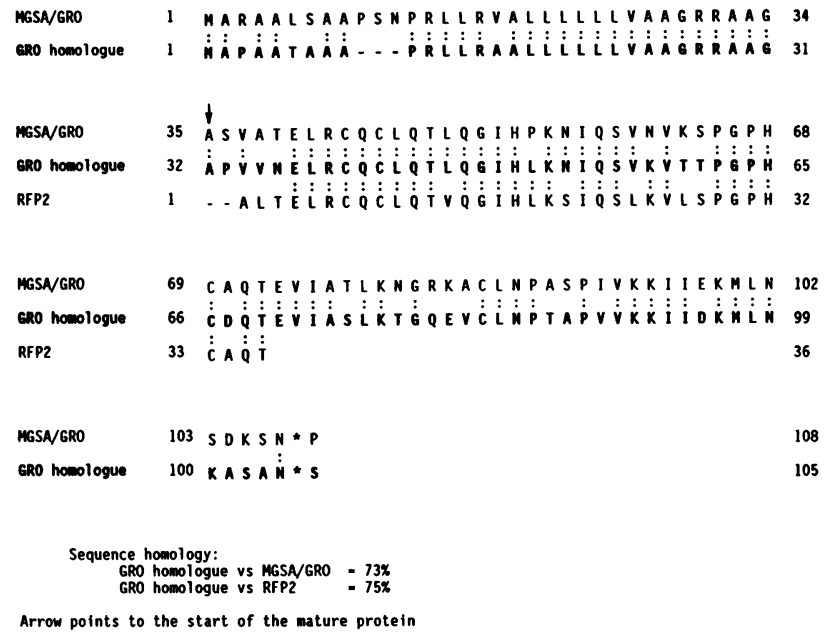

Figure 1. Sequence of the GRO homologue derived from the MM-LDL stimulated rabbit aortic endothelial cell library. The sequence is compared with that of human GRO $\alpha$ (MGSA/GRO), and the partial sequence of a previously described Rabbit GRO (RFP2) (26). (Arrow) Start site of the mature protein.

to GRO. Results from a representative experiment are shown in Fig. 3. MM-LDL stimulation induced more than a threefold increase in detectable GRO surface antigen $(0.281 \pm 0.039$ vs. $0.081 \pm 0.002$ for negative control). Studies with a monoclonal antibody to GRO gave similar results (data not shown). LPS caused a similar increase in the surface expression of GRO. MCP-1 showed minimal surface expression that was not increased with MM-LDL or LPS stimulation (Fig. 3). Treatment

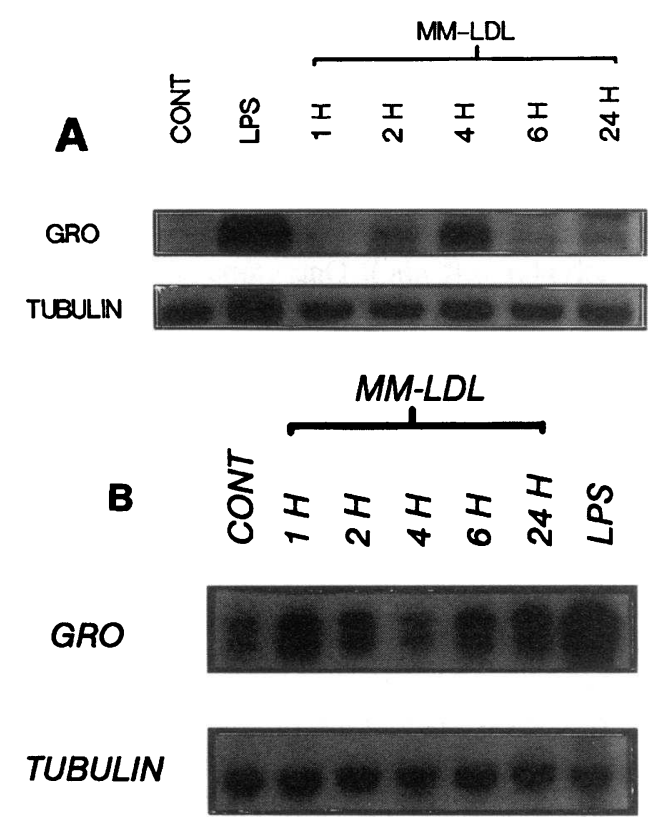

Figure 2. Effect of MM-LDL on mRNA levels of GRO homologue in RAEC $(A)$ or HAEC $(B)$. Endothelial cells were treated for $4 \mathrm{~h}$ with LPS $(1 \mathrm{ng} / \mathrm{ml})$, or for the times indicated with MM-LDL $(125 \mu \mathrm{g} / \mathrm{ml})$. RNA was extracted and Northern blotting performed. Blots were probed with linearized CDNA from the GRO homologue clone for RAEC, or with a full length cDNA probe made to human GRO $\beta$ (which also reacts with GRO $\alpha$ and GRO $\gamma$ ) for the HAEC. The lower band of each figure represents tubulin control.

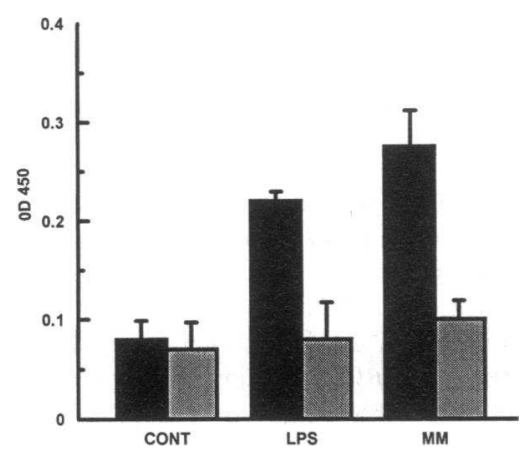

Figure 3. Effect of MMLDL on endothelial surface binding of antibody to GRO or antibody to MCP-1. HAEC were treated for $4 \mathrm{~h}$ with $\mathrm{MM}$ LDL $(125 \mu \mathrm{g} / \mathrm{ml})(M M)$, LPS $(1 \mathrm{ng} / \mathrm{ml})$, or were untreated (CONT). Surface-associated antigen was quantitated by ELISA, using a rabbit polyclonal antibody to

human GRO, or a rabbit polyclonal antibody to MCP-1 as the primary antibody. Data are given as absorbance of the detection reagent and represent the mean $\pm \mathrm{SD}(n=6), P<0.01$ for GRO control vs LPS vs MM. (匹, GRO; 图 MCP-1.)

of cells with MM-LDL for 6-24 h caused a minimal stimulation of GRO secretion into the medium $(0-2 \times$ control). Though GRO peptide was readily detectable on the surface of cells treated with MM-LDL for $4 \mathrm{~h}$, it was present at very low levels $(0.54 \mathrm{ng} / \mathrm{ml})$ in the medium from these cells (Table I). A mixture of GRO peptides added to HAEC in medium for $4 \mathrm{~h}$ at $0.5 \mathrm{ng} /$ $\mathrm{ml}$ did not produce detectable surface associated GRO by ELISA assay. This suggests that GRO detected on the cell surface does not represent nonspecific binding from the medium. The findings for GRO distribution were in contrast to the results for MCP-1. MCP-1 was present in higher levels $(12 \mathrm{ng} / \mathrm{ml})$ in the medium of untreated cells (Table I) but was not detected on the surface of the cells (Fig. 3). Treatment of HAEC for 24 $h$ with MM-LDL increased the levels of both MCP-1 and GRO in the media. LPS strongly stimulated the secretion of both MCP-1 and GRO peptides (Table I).

Anti-GRO polyclonal antibody inhibits monocyte adhesion to MM-LDL treated endothelial monolayers. To determine if a GRO homologue on the surface of endothelial cells plays a role in monocyte binding, MM-LDL-stimulated RAEC and HAEC were preincubated for $15 \mathrm{~min}$ with polyclonal antibody to GRO protein before the addition of monocytes. Data from a representative experiment using RAEC (Fig. $4 \mathrm{~A}$ ) demonstrates that preincubation lowered binding to about $50 \%$ of the levels seen in cells not treated with antibody $(189 \pm 8$ for cells treated with MM-LDL and preimmune IgG, vs. $100.4 \pm 11$ for cells treated with MM-LDL and GRO antibody). Antibody to GRO minimally inhibited monocyte binding to LPS treated cells indicating that other binding molecules (such as VCAM-1, ELAM-1, and ICAM-1, which are known to be induced by LPS) play a more

Table I. Measurement of Secreted Peptides

\begin{tabular}{lccccc}
\hline & \multicolumn{2}{c}{$4 \mathrm{~h}$} & & \multicolumn{2}{c}{$24 \mathrm{~h}$} \\
\cline { 2 - 3 } \cline { 5 - 6 } & GRO & MCP-1 & & GRO & MCP-1 \\
\hline Control & $0.30 \pm 0.06$ & $11 \pm 4$ & & $0.98 \pm 0.18$ & $10 \pm 1$ \\
MM-LDL & $0.54 \pm 0.04$ & $12 \pm 3$ & & $1.86 \pm 0.17$ & $37 \pm 5$ \\
LPS & $10.40 \pm 1.6$ & $67 \pm 3$ & & $24.60 \pm 8.0$ & $241 \pm 16$
\end{tabular}

Levels of GRO peptides and MCP-1 in medium were determined by ELISA assays from human aortic endothelial cells treated for 6 or 24 $\mathrm{h}$ with MM-LDL $(100 \mu \mathrm{g} / \mathrm{ml})$ or LPS $(1 \mathrm{ng} / \mathrm{ml})$. Values are given as $\mathrm{ng} / \mathrm{ml} \pm \mathrm{SD}(n=3$ or 4$)$. 

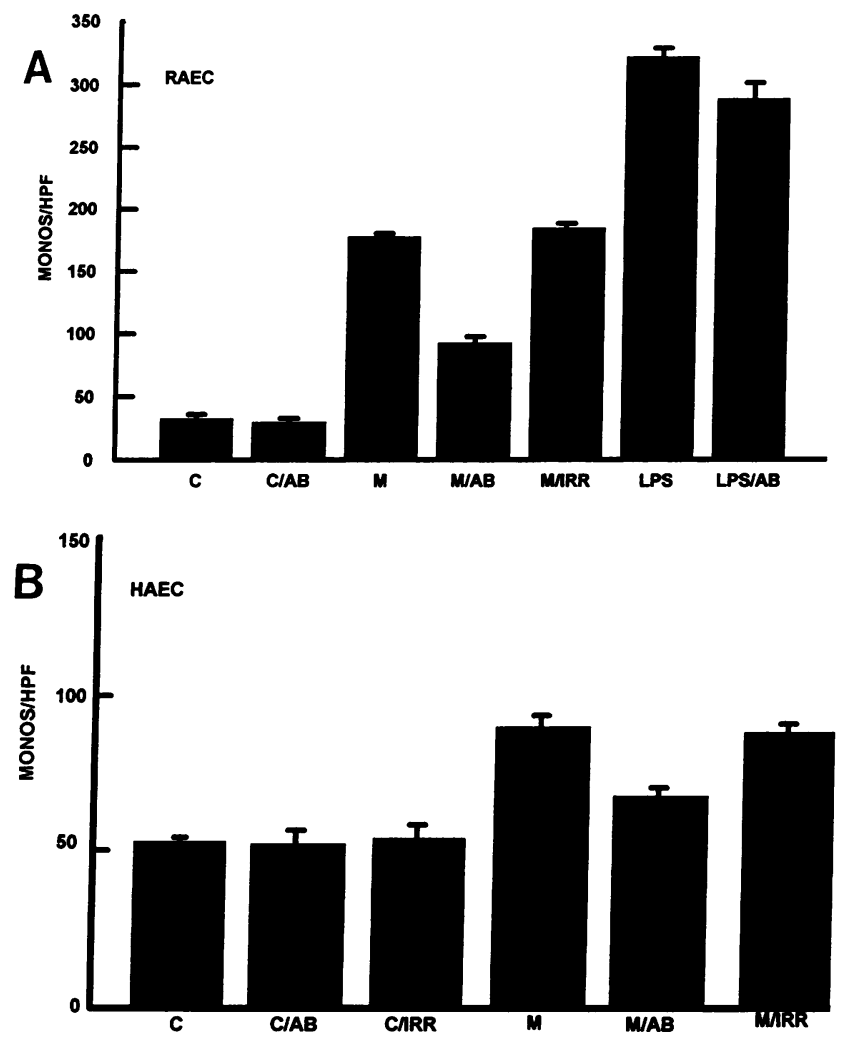

Figure 4. Effect of antibody to GRO protein on monocyte binding induced by MM-LDL. Endothelial monolayers were incubated with either no additives $(C)$, or $125 \mu \mathrm{g} / \mathrm{ml}$ of MM-LDL $(M)$. Monolayers were then exposed to either no additives, polyclonal antiserum made to GRO protein $(A B)$, or IgG from pre-immune serum $(I R R)$, for $15 \mathrm{~min}$. Then monocytes were added to the wells and binding determined. $A$ represents the findings for RAEC, $n=4$ for each condition, $P<0.001$ for $M$ vs $\mathrm{M} / \mathrm{AB}$. $B$ represents the findings for HAEC, $n=4$ for each condition, $P<0.01$ for $\mathrm{M}$ vs $\mathrm{M} / \mathrm{AB}$. Values represent mean \pm SD.

important role in this binding. Monocyte binding to MM-LDLstimulated HAEC was also inhibited by GRO antibody $(91 \pm 3$ for cells treated with MM-LDL and preimmune IgG, vs. $66 \pm 6$ for cells treated with MM-LDL and GRO antibody) (Fig. $4 \mathrm{~B}$ ). The addition of preimmune rabbit IgG to control cells (no MMLDL treatment) either had no effect or minimally stimulated monocyte binding. This experiment is representative of three experiments, all of which gave similar results.

Effects of soluble heparin. We hypothesized that the GRO homologue might be bound to the cell surface by heparan sulfate proteoglycans since GRO proteins are cationic and bind to heparin. To test this hypothesis, we attempted to displace GRO from the surface of the endothelial cells by treatment with heparin (a technique which has previously been shown to be effective for displacing lipoprotein lipase, another heparan sulfate-binding molecule from the endothelial surface). MM-LDL-treated HAEC were exposed to heparin for $8 \mathrm{~min}$ before adding the monocytes to determine surface expression and monocyte binding. ELISA assays demonstrated a reduction in the binding of GRO antibody to the heparin-treated cells (Fig. $5 \mathrm{~A}$ ). This suggests a reduction in the surface expression of the GRO homologue, although it is also possible that heparin masked the GRO antigenic sites. Monocyte binding was also reduced in this setting by $\sim 50 \%$ (Fig. $5 \mathrm{~B}$ ).
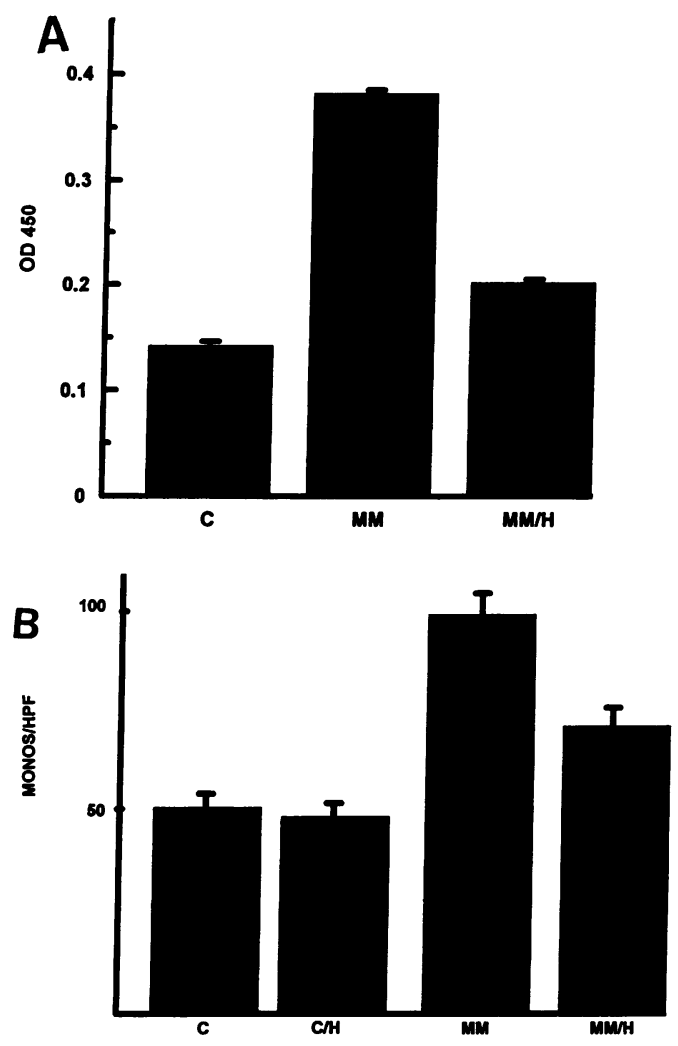

Figure 5. Displacement of GRO from the surface of the endothelial cells by treating endothelial cells with $100 \mu \mathrm{g} / \mathrm{ml}$ of heparin for $8 \mathrm{~min}$ before the determination of surface binding of GRO antibody $(A)$, or before the addition of monocytes for the determination of monocyte binding $(B)$. HAEC were untreated $(C)$, treated with heparin $(C / H)$, treated with MM-LDL $(M M)$, or treated with MM-LDL and heparin $(M M / H) . n=4, P=0.001$ for $\mathrm{MM}$ vs $\mathrm{MM} / \mathrm{H}$ in $A, P=0.01$ for $\mathrm{MM}$ vs $\mathrm{MM} / \mathrm{H}$ in $B$.

\section{Discussion}

The mechanism by which MM-LDL induces the selective binding of monocytes to stimulated-endothelial monolayers has not been previously elucidated. Expression screening of a cDNA library prepared to MM-LDL-treated endothelial cells for a protein inducing monocyte, but not PMN binding, resulted in the isolation of a cDNA highly homologous to GRO proteins. The sequence of this GRO homologue differed from a previously published partial sequence of a rabbit GRO homologue obtained from inflammatory exudate fluid (27), indicating that more than one member of this family is present in rabbit as well as human cells. The finding that MM-LDL induces the mRNA for a GRO homologue (Fig. 2) in RAEC and HAEC, and increases the surface protein expression of a molecule that binds antibody to GRO in HAEC (Fig. 3) suggests that chemokines of this group may play a role in monocyte binding to MM-LDL-stimulated cells. This is further supported by results which show that anti-GRO polyclonal antibody partially inhibited monocyte binding to MM-LDL-stimulated endothelial cells (Fig. 4).

The chemokine superfamily has traditionally been subdivided into two subfamilies on the basis of structural and physiological properties (7); the C-X-C family has been considered to act on neutrophils, while the C-C family acts on monocytes. The C-X-C subfamily whose members include GRO homo- 
logues, have an intervening amino acid residue between the first two of four conserved cysteines. This family has been shown to have neutrophil chemotactic and activating properties $(8,9$, $15,28,29)$. The $\mathrm{C}-\mathrm{C}$ subfamily includes monocyte chemoattractant protein-1, lacks the intervening amino acid, and has been shown to induce monocyte stimulation and localization (30). The results from these studies as well as others (16) suggest that monocytes also serve as target cells for members of the $\mathrm{C}$ $\mathrm{X}-\mathrm{C}$ subfamily, implying that the subdivision of chemokine biological activities for specific cell types along the lines of the conserved cysteine structural motif is oversimplified.

Previous investigations have concentrated on the activities of chemokines as soluble proteins that were thought to act as chemotactic factors attracting leukocytes exposed to a gradient of this soluble molecule. Rot has shown that IL-8 bound to the surface of endothelial cells can mediate migration (haptotaxis) $(31,32)$. Our findings also suggest that chemokines may be active when attached to the endothelial surface. There are several possible mechanisms to explain the presence of GRO homologues on the endothelial surface. The protein may associate directly with the cell membrane via a transmembrane region. Analysis of this rabbit Gro homologue however shows no hydrophobic stretches that could function as a membrane anchor region. Alternatively, it is well established that members of the chemokine family bind strongly to heparin $(8,33,34)$. The principal constituent of the cultured endothelial cell luminal glycocalyx is a closely related proteoglycan, heparan sulfate (HSPG) (see reference 35 for review). Secreted GRO could therefore bind to surface-associated proteoglycans. The binding of GRO peptide to HSPG would be consistent with a large number of studies that have previously shown that HSPGs associate with heparin-binding growth factors, such as aFGF, PDGF, and GM-CSF, both on the luminal surface (36) and in the subendothelial matrix (see reference 37 for review). Nuclear magnetic resonance (NMR) and X-ray structural analysis of IL-8 and Xray analysis of PF- 4 show a carboxyl terminal alpha-helix that is representative of an almost idealized amphiphilic helix (3840). The hydrophobic residues on one side of the helix are involved in anchoring the helix to the beta sheet of the IL-8/ PF-4 structure. The positively charged residues on the other face could easily be envisaged to be involved in heparin binding. This region of platelet factor 4 has been shown to be involved in heparin binding (41), and in IL-8 binding (42). A helical wheel diagram of the GRO homologue reported here (data not shown) as well as the human GRO proteins (43) show evidence of an amphiphilic helix with a positively charged face which would be consistent with a site for interaction with cell surface glycosaminoglycans. This could be the means whereby GRO is bound to the endothelial surface.

Our findings also suggest that heparin displaces GRO from the endothelial surface. These results suggest that the GRO protein attaches to the surface of the endothelium by a heparan sulfate link. An interesting additional finding was the concomitant decrease in monocyte adhesion to the heparin-treated endothelial monolayer, approximately equivalent to the inhibition achieved by anti-GRO antibody. Although we cannot conclude that the heparin inhibition of binding is the result of release of GRO proteins, this experiment implies that a heparin-binding protein is intimately involved in monocyte adhesion. Other members of the C-X-C family have been shown to activate neutrophils and lymphocytes when present in a bound form. Recent reports have shown that when IL-8 (a member of the C-X-C family of chemokines) binds to HSPG it becomes more active then when unbound, and that $\mathrm{COOH}$ terminal truncation of the amphiphilic helix eliminated the affinity of IL-8 for heparin sepharose $(41,42)$. Tanaka and colleagues $(44)$ have recently shown that MIP- $1 \beta$ is immobilized on lymph node endothelium and can induce binding of T-lymphocytes to VCAM-1.

Although not clearly defined at this time, a role for GRO in the attachment and activation of monocyte adhesion would be consistent with the multistep model of leukocyte/endothelial adhesion described previously (45). GRO could be involved in the monocyte adhesion to the MM-LDL-stimulated endothelium in the following manner. The GRO that is produced and released by the MM-LDL-stimulated endothelial cells could remain immobilized on the surface of the endothelial cell to serve as an attachment factor and/or more likely an activator of the monocyte for subsequent steps in the adhesion process. Our findings suggest that GRO can serve as an adhesion factor in this in vitro static system. The pathophysiologic role of GRO in nonstatic conditions and in vivo will require further studies.

We have previously shown that MM-LDL induces the synthesis of MCP-1, a soluble chemotactic factor that is secreted into the medium by the cells. Why might cells produce both soluble and bound leukocyte-activating molecules? In areas of rapid flow, such as in large arteries, endothelial tethering molecules may not provide sufficiently strong leukocyte endothelial interactions to ensure localization or exposure to soluble chemotactic factors. The juxtacrine activation of leukocytes by bound chemokines may strengthen this binding and help present the chemotactic gradient. Such a juxtacrine activation has been shown for platelet activating factor (46).

By utilizing surface-associated chemokines to modulate the activation and adhesion of leukocytes, the vascular endothelium would be able to take advantage of a versatile collection of possible regulatory schemes. The concentration of bound chemokines could be regulated either at the level of protein synthesis or at the subsequent stage of association with the luminal surface. Specific concentrations, in turn, may play an important role in preferentially attaching cells to the surface of the vascular wall. Even more intriguing is the possibility that different members of the chemokine family could function in close coordination with each other, either through physical or functional associations. A growing number of reports have shown members of the chemokine family to cross-react with the same cell surface receptors $(47,48)$, and it has been suggested that different chemokine moieties may bind to one another to form heterodimers (49). In addition, glycocalyx composition could possibly play an important regulatory role. The manner by which GRO homologues act to induce leukocyte adhesion to the endothelium is potentially complex, and may be part of a flexible and inducible mechanism for regulating inflammation and tissue repair.

\section{Acknowledgments}

We would like to thank Drs. Ann Richmond and Anthony Valente for providing monoclonal antibodies for these studies.

This work was supported by National Institutes of Health grant HL30568, Tobacco Related Diseases Project RT 372, and the Laubisch Fund. D. Schwartz was supported by a Fellowship from the American Heart Association.

\section{References}

1. Lusis, A. J., J. A. Berliner, and A. M. Fogelman. 1991. Lipoproteins and monocyte recruitment in early atherogenesis. In Lipoproteins and the Pathogenesis 
of Atherosclerosis. J. Sheperd et al., editors. Elsevier Science Publishing Co., New York. 137-145.

2. Berliner, J. A., M. C. Territo, A. Sevanian, S. Ramin, J. A. Kim, B. Bamshad, M. Esterson, and A. M. Fogelman. 1990. Minimally modified low density lipoprotein stimulates monocyte endothelial interactions. J. Clin. Invest. $85: 1260-1266$

3. Rajavashisth, T. B., A. Andalibi, M. C. Territo, J. A. Berliner, M. Navab, A. M. Fogelman, and A. J. Lusis. 1990. Induction of endothelial cell expression of granulocyte and macrophage colony-stimulating factors by modified LDL. Nature (Lond.). 344:254-257.

4. Cushing, S., J. A. Berliner, A. J. Valente, M. C. Territo, M. Navab, F. Parhami, R. Gerrity, C. J. Schwartz, and A. M. Fogelman. 1990. Minimallymodified low density lipoprotein induces monocyte chemotactic protein 1 in human endothelial cells and smooth muscle cells. Proc. Natl. Acad. Sci. USA. 87:5134-5138.

5. Berliner, J. A., M. C. Territo, L. Almada, A. Carter, E. Shafonsky, and A. M. Fogelman. 1986. Monocyte chemotactic factor produced by large vessel endothelial cells in vitro. Arteriosclerosis. 6:254-258.

6. Berliner, J. A., D. S. Schwartz, M. C. Territo, A. Andalibi, L. Almada, A. J. Lusis, D. Quismorio, Z. T. Fang, and A. M. Fogelman. 1993. Induction of chemotactic cytokines by MM-LDL. In The Chemokines. I. J. Lindley et al., editors. Plenum Press, New York. 13-18.

7. Bork, R. W., K. L. Svenson, M. Merhrabian, A. J. Lusis, A. M. Fogelman, and P. A. Edwards. 1992. Mechanisms controlling competence gene expression in murine fibroblasts stimulated with MM-LDL. Arterioscler. Thromb. 12:800806.

8. Oppenheim, J. J., C. O. C. Zachariae, N. Mukaida, and K. Matsushima. 1991. Properties of the novel proinflammatory supergene "intercrine" cytokine family. Annu. Rev. Immunol. 9:617-648.

9. Haskill, S., A. Peace, J. Morris, A. S. Sporn, A. Anisowicz, S. W. Lee, T. Smith, G. Martin, P. Ralph, and R. Sager. 1990. Identification of three related human GRO genes encoding cytokine functions. Proc. Natl. Acad. Sci. USA. 87:7732-7736.

10. Tekamp-Olson, P., C. Gallegos, D. Bauer, J. McClain, B. Sherry, M. Fabre, S. vanDeventer, and A. Cerami. 1990. Cloning and characterization of cDNAs for murine macrophage inflammatory protein 2 and its human homologues. J. Exp. Med. 172:911-919.

11. Wen, D., A. Rowland, and R. Derynck. 1989. Expression and secretion of gro/MGSA by stimulated human endothelial cells. EMBO (Eur. Mol. Biol. Organ.) J. 8:1761-1766.

12. Richmond, A., D. H. Lawson, D. W. Nixon, J. S. Stevens, and R. K Chawla. 1983. Extraction of a melanoma growth-stimulatory activity from culture medium conditioned by the $\mathrm{Hs} 0294$ human melanoma cell line. Cancer Res. 43:2106-2112.

13. Schroeder, J. M., N. L. M. Pearson, and E. Christophers. 1990. Lipopolysaccaride-stimulated human monocytes secrete, apart from neutrophil-activation peptide 1/interleukin 8 , a second neutrophil-activating protein. J. Exp. Med. 171:1091-1100

14. Watanabe, K., K. Kinishi, M. Fujioka, S. Kinoshita, and H. Nakagana 1989. The neutrophil chemoattractant produced by the rat kidney epithelial line NRK-52E is a protein related to KC/GRO protein. J. Biol. Chem. 264:1955919563.

15. Moser, B., I. Clark-Lewis, R. Zwahlen, and M. Baggiolini. 1990. Neutrophil-activating properties of the melanoma growth-stimulatory activity. $J$. Exp. Med. 171:1797-1802

16. Walz, A., F. Meloni, I. Clark-Lewis, V. von Tscharner, and M. Baggiolini. 1991. $\left[\mathrm{Ca}^{+2}\right]_{i}$ changes and respiratory burst in human neutrophils and monocytes induced by NAP-1/Interleukin-8, NAP-2, and gro/MGSA. J. Leukocyte Biol. 50:279-286.

17. Fogelman, A. M., F. Elahi, K. Sykes, B. S. Van Lenten, M. C. Territo, and J. A. Berliner. 1988. A modification of the recalde method for the isolation of human monocytes. J. Lipid Res. 29:1243-1247.

18. Sparrow, C. P., S. Parthasarathy, and D. Steinberg. 1988. Enzymatic modification of LDL by purified lipoxygenase plus phospholipase A2 mimics cell-mediated oxidative modification. J. Lipid Res. 29:745-753.

19. Parhami, F., Z. T. Fang, A. M. Fogelman, A. Andalibi, M. D. Territo, and J. A. Berliner. 1993. MM-LDL induced inflammatory responses in endothelial cells are mediated by cAMP. J. Clin. Invest. 92:471-478.

20. Chomczynski, P. and N. Sacchi. 1987. Single-step method of RNA isolation by acid guanidinium thiocyanate-phenol-chloroform extraction. Anal. Biochem. 162:156-159.

21. Guebler, U. and B. J. Hoffman. 1983. A simple and very efficient method for generating cDNA libraries. Gene (Amst.). 25:270-274.

22. Aruffo, A. and B. Seed. 1990. Molecular cloning of a CD28 cDNA by a high efficiency COS cell expression system. Proc. Natl. Acad. Sci. USA. 84:85738579 .

23. Hession, C., L. Osborn, D. Goff, G. Chi-Rosso, C. Vassalo, M. Pasek, C. Pittack, C., R. Tizard, S. Goelz, K. McCarthy, S. Hopple, and R. Lobb. 1990. Endothelial Leukocyte Adhesion Molecule-1: Direct expression cloning and functional interactions. Proc. Natl. Acad. Sci. USA. 87:1673-1677.
24. Cushing, S. D., and A. M. Fogelman. 1992. Monocytes may amplify their recruitment into inflammatory lesions by inducing Monocyte Chemotactic Protein Arterioscler. Thromb. 12:78-82.

25. Takeya, M., T. Yoshimura, E. J. Leonard, T. Kato, H. Okabe, and K. Takahashi. 1991. Production of MCP-1 by malignant fibrous histiocytoma. Exp. Pathol. (Jena). 54:61-71.

26. Shimada, K., P. Gill, J. Silbert, and W. Douglas. 1981. Involvement of cell surface heparin sulfate in the binding of lipoprotein lipase to cultured bovine endothelial cells. J. Clin. Invest. 68:995-1002.

27. Jose, P. J., P. D. Collins, J. A. Perkins, B. C. Beaubien, N. F. Totty, M. D. Waterfield, J. Hsuan, and T. J. Williams. 1991. Identification of a second neutrophil chemoattractant cytokine generated during an inflammatory reaction in the rabbit peritoneal cavity in vivo. Biochem. J. 278:493-497.

28. Sager, R., S. Haskill, A. Anisowicz, D. Trask, and M. C. Pike. 1991. Gro: a novel chemotactic cytokine. In Chemotactic Cytokines. J. Westwick, I. D. J. Lindley, and S. L. Kunkel, editors. Plenum Press, New York. 73-77.

29. Iida, N. and G. R. Grotendorst. 1990. Cloning and sequencing of a new gro transcript from activated human monocytes: Expression in leukocytes and wound tissue. Mol. Cell. Biol. 10:5596-5599.

30. Wolpe, S. D. and A. Cerami. 1989. Macrophage inflammatory proteins and 2: Members of a novel superfamily of cytokines. FASEB (Fed. Am. Soc. Exp. Biol.) J. 3:2565-2573.

31. Rot, A. 1992. Endothelial cell binding of NAP-1/IL-8L: role in neutrophil emigration. Immunol. Today. 13:291-294.

32. Rot, A. 1992. Neutrophil attractant/activation protein-1 (interleukin-8) induces in vitro neutrophil megration by haptotactic mechanism. Eur. J. Immunol. 23:303-306.

33. Busch, C., J. Dawes, D. S. Pepper, and A. Wasteson. 1980. Binding of platelet factor 4 to cultured human umbilical vein endothelial cells. Thromb. Res. 19:129-137.

34. Loscalzo, J., B. Melnick, and R. I. Handin. 1985. The interaction of platelet factor four and glycosaminoglycans. Arch. Biochem. Biophys. 240:446-455.

35. Gallagher, J. T., M. Lyon, and W. P. Steward. 1986. Structure and function of heparan sulphate proteoglycans. Biochem. J. 236:313-325.

36. Raines, E. W. and R. Ross. 1992. Compartmentalization of PDGF on extracellular binding sites dependent on exon-6-encoded sequences. J. Cell Biol. 116:533-543.

37. Jackson, R. L., S. J. Busch, and A. D. Cardin. 1991. Glycosaminoglycans: Molecular properties, protein interactions, and role in physiological processes. Physiol. Rev. 71:481-539.

38. Clore, G. M., E. Appella, M. Yamada, K. Matsushima, and A. M. Gronenborn. 1990. Three dimensional structure of Interleukin-8 in solution. Biochemistry. 29:1689-1696.

39. Clore, G. M., E. Appella, M. Yamada, K. Matsushima, and A. M. Gronenborn. 1989. Determination of the secondary structure of interleukin-8 by nuclear magnetic resonance spectroscopy. J. Biol. Chem. 264:18907-18911.

40. St. Charles, R., D. A. Walz, and B. F. Edwards. 1989. The three-dimensional structure of bovine platelet factor 4 at 3.0-A resolution. J. Biol. Chem. 264:2092-2099.

41. Loscalzo, J., B. Melnick, and R. I. Handin. 1985. The interaction of platelet factor four and glycosaminoglycans. Arch. Biochem. Biophys. 240:446-455.

42. Webb, L. M. C., M. U. Ehrengruber, I. Clark-Lewis, M. Baggiolini, and A. Rot. 1993. Binding to heparan sulfate or heparin enhances neutrophil responses to interleukin 8. Proc. Natl. Acad. Sci. USA. 90:7158-7162.

43. Schiffer, M., and A. B. Edmunson. 1967. Use of helical wheels to represent the structures of proteins and to identify segments with helical potential. Biophys. J. 7:121-135.

44. Tanaka, Y., D. H. Adams, S. Hubscher, H. Hirano, U. Sieberlist, and S Shaw. 1993. T-cell adhesion induced by proteoglycan-immobilized cytokine MIP1B. Nature (Lond.). 361:79-82.

45. Butcher, E. C. 1991. Leukocyte-endothelial cell recognition: Three (or more) steps to specificity and diversity. Cell. 67:1033-1036.

46. Zimmerman, G. A., T. M. McIntyre, M. Meena, and S. M. Prescott. 1990 Endothelial cell-associated Platelet-activating Factor: A novel mechanism for signaling intercellular adhesion. J. Cell Biol. 110:529-540.

47. Mukaida, N., A. Hishinuma, C. O. C. Zachariae, J. J. Oppenheim, and K. Matsushima. 1991. Regulation of human interleukin 8 gene expression and binding of several other members of the intercrine family to receptors for interleukin 8. In Chemotactic Cytokines. J. Westwick, I. D. L. Lindley, and S. L. Kunkel, editors. Plenum Press, New York. 31-38.

48. Moser, B., C. Schumacher, V. von Tscharner, I. Clark-Lewis, and M. Baggiolini. 1991. Neutrophil-activating peptide 2 and gro/melanoma growth stimulatory activity interact with neutrophil-activation peptide 1/interleukin 8 receptors on human neutrophils. J. Biol. Chem. 266:10666-10671.

49. Cheng, Q. C., J. H. Han, H. G. Thomas, E. Balentien, and A. Richmond 1992. The melanoma growth stimulatory activity receptor consists of two proteins J. Immunol. 148:451-456. 